\title{
Advancing Opportunities in Renewable Energy Production
}

\author{
István Vokony ${ }^{1}$, Balázs Bonda ${ }^{2}$, Attila Talamon ${ }^{3}$, Máté Nagy ${ }^{4}$, Gergő Holló ${ }^{5}$
}
${ }^{1}$ Hungarian Young Professionals in Energy, World Energy Council, Budapest, Hungary vokony.istvan@vet.bme.hu
${ }^{2}$ Hungarian Young Professionals in Energy, World Energy Council, Budapest, Hungary balazs.bonda@gmail.com
${ }^{3}$ Hungarian Young Professionals in Energy, World Energy Council, Budapest, Hungary ${ }^{3}$ Institute of Architecture, Szent István University, Budapest, Hungary
${ }^{3}$ Centre for Energy Research, Hungarian Academy of Sciences, Budapest, Hungary talamon.attila@energia.mta.hu, talamon.attila@ybl.szie.hu
${ }^{4}$ Hungarian Young Professionals in Energy, World Energy Council, Budapest, Hungary matthewbig@gmail.com
${ }^{5}$ Hungarian Young Professionals in Energy, World Energy Council, Budapest, Hungary gergo.hollo@gmail.com

\begin{abstract}
The organization - WEC Hungarian Young Professionals in Energy (HYPE) - in line with WEC's (World Energy Council) visions aims for the dissemination of the principle of sustainable energy development in Hungary. The HYPE's goals are to represent the Hungarian energy sector 's viewpoint at national, regional and international events; to introduce and evaluate the key energy issues by preparing studies; and to foster the development of future energy professionals.

Sustainable development and the strongly related secure supply is one of the most important questions arise among energy engineering issues. One of the first answers for the above complex problem is renewable energy sources. To achieve success, that is to integrate renewable systems, it is essential to design, control and support engineering and financial background of electrical engineering structures. (The question is even more important for Hungary, where neither energy nor financial resources are abundant at all.)

The long term energy politics of the European Union aims to provide well-being for its citizens. It can be derived to several sub-notions which the EU would also like to support therefore, such as the appropriate operation of the economy, access to electric energy for both households and corporate consumers on reasonable prices and attention to environmental protection and sustainable growth in the meanwhile.

As of the above mentioned goals, the EU is committed to maintain the Europe 2020 strategy (20-2020 initiative) which aims to reduce green-house gas emission by $20 \%$, increase renewable energy sources to 20\% (from 8.5\%) and increase energy efficiency by $20 \%$ until 2020. The EU has launched several actions to achieve the 20-plans. Integration of electricity markets, development of networks and establishing investment capital is in progress.

In the followings a chronology and overview will be presented to give a better understanding the aims, subsidy systems and energy politics' targets. The study of WEC Hungarian Young Professionals in Energy brings opinion on the National Action Plan as well which is especially recommended to our readers.
\end{abstract}

Keywords: Renewable Energy, Production, Energy Policy, HYPE, WEC, Hungary 


\section{INTRODUCTION - WEC HYPE}

World Energy Council (WEC), founded in 1924, is one of the most influential energy politics organizations in the world. The mission of WEC is 'to promote sustainable energy supply and helping the most efficient use of energy for all people'.

The foundation of the Hungarian organization, Hungarian Young Professionals in Energy (HYPE), was decided in 2012 by us. Our members are young professionals strongly related to the energy industry with motivation and vocation towards good work. Our goal is to provide opportunity to obtain knowledge beyond university education and constructive professional discussions. As a result of our work, we have published a report where we have summarized the related questions and basic knowledge of the semester. [1]

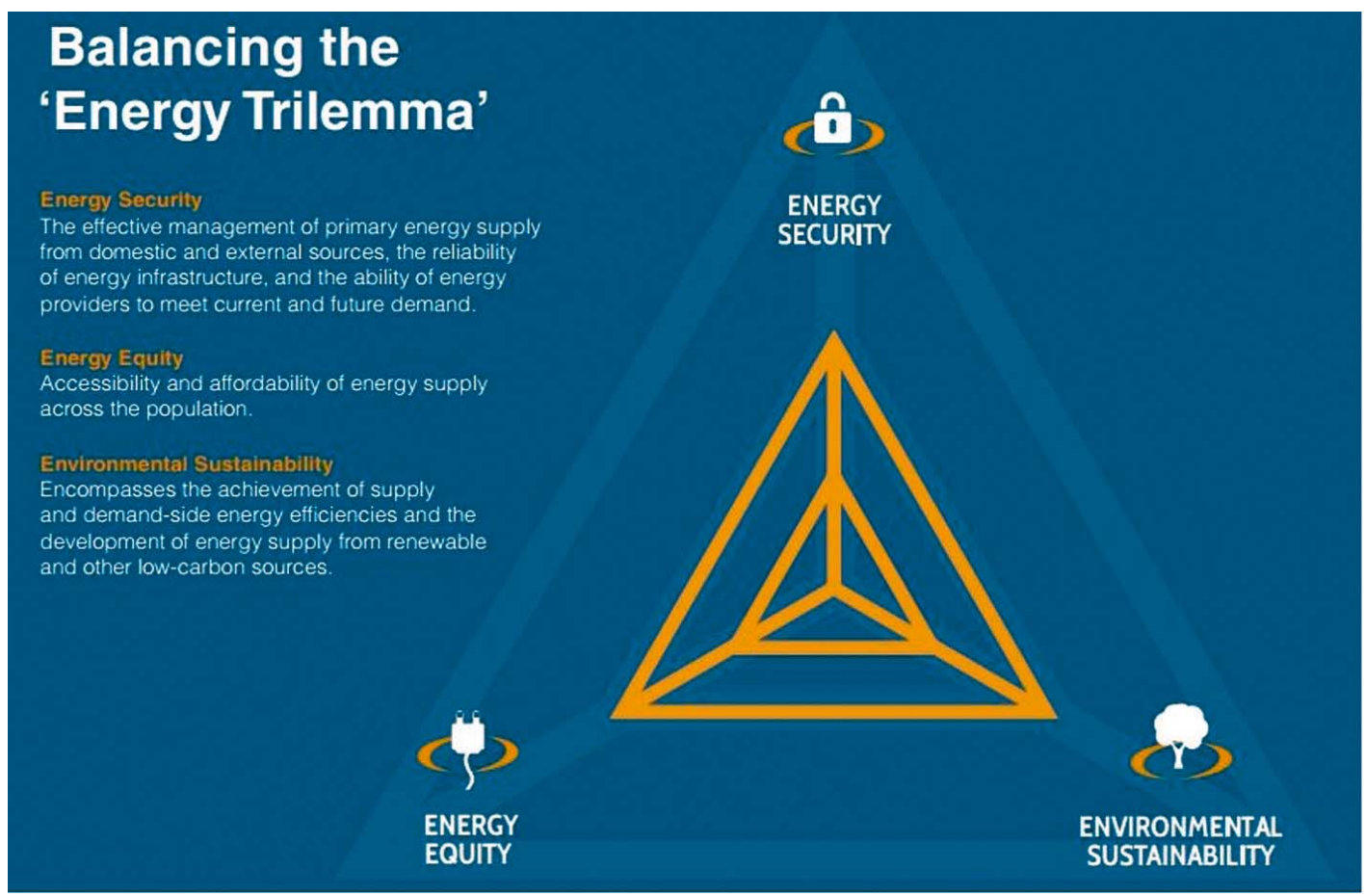

Figure 1. The WEC Energy Trilemma

The topic of the 2012-13 autumn semester was the analysis of competitivity of renewable energy sources and their potential role in the near future of the European and the Hungarian energy industry. The report consists of 5 chapters, where the 5 th chapter is about the reasonable improvement opportunities and research of breaking points on renewable energy production. To have an acceptable analysis, it is necessary to take a look at the previous goals and facts and from Hungary's perspective, it is also necessary to take a look at the 'Republic of Hungary National Renewable Energy Action Plan 2010-2020' document as the revisit of the commitments will soon be at the doors. Below, you will find the development of the chapter whereas you can find the whole report and other half-year reports and documents at the WEC HYPE web page (http://www.wec.hu) or at the members of the Hungarian organization. 


\section{CHRONOLOGY}

The goal of the long term energy politics of the European Union is to secure welfare, a well working economic system, access to energy products on the market (in both private and corporate cases) at reasonable prices with respect to environmental aspects and shift towards sustainable development. [2]

The energy politics of the EU has 3 main goals: to secure supply, to increase competitively and to keep environmental aspects in eyesight. These are the baseline criteria of energy cooperation in the EU since the 1995 Committee White Book. [3]

\subsection{Between 1951-1991}

The energy politics, besides the fact that from 3 base contracts 2 was made in the same topic - The Paris Contract (1951) and the Euroatom, Rome Contract (1957) - was considered as a member country decision and the topic was slow to be transferred to the common EU topics.

The committee has proposed a common energy strategy in 1974 already, which was approved by the council. The initiative, as a result of the oil crisis, aimed to rationalize the energy usage and reduce the oil import dependency. Energy production form local or less dependent sources was aimed to be increased by investments to the nuclear energy sector and by stabilizing the coal production. [4]

In 1986, complex energy politics goals have been determined along the White Book of the committee, which aimed to change the energy sector besides rationalization and reduction of consumption. The goals have been reflecting the changes on the energy market. The supply was abundant, besides rationalization, the goal was to reduce prices. Further development of nuclear energy was secondary.

The idea of a common internal market was made at the time, of which a determining element was the energy politics, as it is a direct influential factor on the European industry. To reach this goal, unification of regulations made to be one of the central elements of the common energy politics at multiple topics (energy subventions, state monopoly, prices). The protests of member countries have made this conversion difficult and as a result, only the unification of the regulations was the area where positive changes have been achieved. [5]

\subsection{The Energy Charta (1991)}

Eastern-European changes at the turn of 80-s and 90-s motivated the born of the Energy Charta signed in Hague in 1991. At the 1990 Dublin sessions of The European Council, the Dutch prime minister proposed to have strong energy industry cooperation with post-soviet countries with the goal to advance the economic development and improve the security of energy supply of these countries. The increase of energy efficiency and the focus on environmental goals was also at the most important topics. The Charta has special provisions on transparency, sovereignty, taxes, environment and the state and privatized companies. The Charta has been signed by 51 countries and the European Union with which it has overcome its own goals. Russia however, has not ratified the contract yet, which makes the realization of the aims more difficult. [6] 


\subsection{The Green Book (1996)}

The Green Book is an important mile stone in the development of the European Union energy politics. If Europe wishes to reach the economic, social and environmental goals, it has to find solution to the most important challenges, to the main energy related questions, as the increasing import dependency, the increase of oil and gas prices the climate change, the increasing demand and the obstacles on a completely competitive internal energy market. The EU has to use its position as the second largest energy market in the world and the first in driving demand and use of renewable energy resources.

The committee requested the member countries to do whatever they can do to establish such a notion as European Energy Politics with 3 main goals:

- Sustainability - an active fight against climate change with respect to the renewable resources and the energy efficiency;

- Competitiveness - the increase of efficiency through the establishment of energy network; a truly competitive internal market;

- Supply security - an international synchronization of European Union demand and supply [7]

\subsection{The White Book (1997)}

Renewable energy sources are not evenly or sufficiently exploited in the European Union. Although these sources are available in significant quantities in many countries and the economic potential is also substantial, the proportion of the renewable sources is minuscule, less than $6 \%$ of the total gross inland energy consumption of the European Union, which is projected to constantly grow. Collaboration is necessary either on Community and Member State level to be able to meet this challenge.

Generally Europe is at the forefront of several renewable energy technology fields. It resulted significant employment growth in the associated industries of the European Union, of which hundreds of firms, particularly small- and medium sized enterprises are affected in the raw material construction and production, without considering the additional services. The estimated turnover of the new renewable energy technologies worldwide (excluding the large hydroelectric stations and traditional biomass plants) exceeds the ECU billion, of which the Union has more than $30 \%$, share". [8]

\subsection{The Green Book (2006)}

The Green Book states, that the EU has entered into a new energy era, which requires changes in the way of dealing with:

- investments in the energy sector,

- import dependency,

- reserves,

- global demand for energy, 
- rising oil and gas prices,

- climate change,

- "not well developed" competitive internal energy market.

To establish a developing European energy policy will be a long term challenge. This needs a clear but at the same time flexible framework: it has to represent a common approach citated from the highest level, and to be flexible it needs periodic updating. To support this process the Commission proposed a Strategic EU Energy Review be presented to the Council and Parliament on a regular basis, covering the issues identified on the Green Book.

The Green Book has identified six key areas to be focused on:

- Energy for growth and jobs in Europe: completing the internal European electricity and gas markets

- An Internal Energy Market that guarantees security of supply: solidarity between Member States

- Tackling security and competitiveness of energy supply: towards a more sustainable, efficient and diverse energy mix

- An integrated approach to tackling climate change

- Encouraging innovation: a strategic European energy technology plan

- Towards a coherent external energy policy

These six priority areas form and contain the concrete action plan for the European Energy Policys' three main objective:

- Sustainability,

- Competitiveness,

- Security of supply,

which objectives partially cover the Energy Trilemma factors. [10]

\subsection{The Energy Legislation Packages}

The legal framework beside "The Books" consists of Energy Legislation Paskages. These packages are basically Directives and Regulations.

The First Energy Legislation Package

The First Energy Legislation Package allowed the opening of the electricity and gas market and a gradual introduction of competition. Moreover, it imposed broad unbundling requirements to integrated companies. It consist of two packages:

- Directive 96/92/EC "Electricity Directive": Well-competitive internal energy market can increase the efficiency of the European system and reinforce the security of electricity supply and the competitiveness of the European economy.

- Directive 98/30/EC "Gas Directive": Internal market shall favour the interconnection and interoperability of the system, for instance through compatible qualities of the gas. The Second Energy Legislation Package 
The Second Energy Legislation Package

The Second Energy Legislation Package focused more on the concepts of unbundling and third party access. The package defined the need for independent regulatory authorities.

The Second Package has two Directives:

- Directive 2003/54/EC: Member States can impose public service obligations on electricity undertakings, which may relate to security of supply, regularity, quality and environmental protection.

- Directive 2003/55/EC: An unbundling requirement of independence of different activities at least in terms of the legal form, organisation and decision making.

and two regulations:

- Regulation 1228/2003/EC: In light of cross-border exchanges of electricity, some mechanisms are introduced for the cross-border transit of electricity, transmission charges and allocation of available capacities.

- Regulation 1775/2005: In order to guarantee the access to the natural gas transmission network, it is established that the access must be guaranteed on a non-discriminatory basis.

The Third Energy Legislation Package

The Third Energy Legislation package established a new unbundling regime and more clearly defined the duties of national regulatory authorities, including the cooperation with the Agency for the Cooperation of Energy Regulators (ACER). It also improved consumers' rights, provided a number of measures for the functioning of the internal electricity and gas market, and promoted regional solidarity and national emergency measures in the event of severe disruptions of gas supply.

The Third Package has two Directives:

- Directive 2009/72/EC: Member States must take actions for the protection of vulnerable customers, first of all by defining the concept of vulnerable customers with reference to energy poverty, and secondly, by prohibiting disconnection of these customers in critical times.

- Directive 2009/73/EC: The provisions concerning the three different unbundling options apply also to the gas market, and in particular to transmission, distribution, storage and LNG facilities, and three regulations:

- $\quad$ Regulation (EC) No. 713/2009: An Agency for the Cooperation of Energy Regulators (ACER) is established, in order to monitor and coordinate the development of energy regulation in the internal energy market as well as the activity of the national regulatory authorities. Further relevant tasks in the field of the promotion of market integrity and transparency were assigned to ACER by Regulation (EC) 1227/2011 (so-called "REMIT").

- Regulation (EC) No. 714/2009: In light of the access to the network for cross-border exchanges in the electricity sector, the previous Regulation (EC) No 1228/2003 is repealed and ENTSO for Electricity is established.

- Regulation (EC) No. 715/2009: as for the access to the natural gas transmission networks, the previous Regulation (EC) No 1775/2005 is repealed and ENTSO for Gas is established. 
ENTSO-E and ENTSO-G operate in order to promote the coordination among TSOs, and cooperate with ACER, for instance, in the creation of network codes regulating access and other technical issues. [11]

\section{HUNGARY'S RENEWABLE ENERGY UTILISATION ACTION PLAN FOR 2010-2020}

„We need to find the breakout points, the future-industries which can boost the whole economy. The means by which the breakout points are connected have to be found, which through the these points are woven into fabric to be the most important economic margin drivers: local conditions and labour intensive enterprises such as health care industry, tourism, green agriculture, renewable energies, water-based economy development, vehicle industry, transit industry, food industry, business services, research and development." [9]

By the end of the period based on cheap energy and by the results of the efforts to reduce factors causing climate change, in the 21 th century mankind returns to the foundations of existence on Earth. Elements of the environment and natural resources: soil, water, air quality, energy and the access to these will be the key issue. Therefore the success of a country such as ours with the geopolitical and natural capabilities significantly depends on how the economic model built on traditional energy sources can be switched to an alternative model. Also a crucial question if the external effects of the replaced model (import dependence, security of supply, energy poverty) can be reduced, or converted into a positive balance while aspiring to equalise between the environmental elements and system provided services and developmental needs.

The Renewable Energy Utilisation Action Plan of Hungary (REAP) has been compiled in the spirit of the above, indicating a new era from 2010 in the energy policy of Hungary.

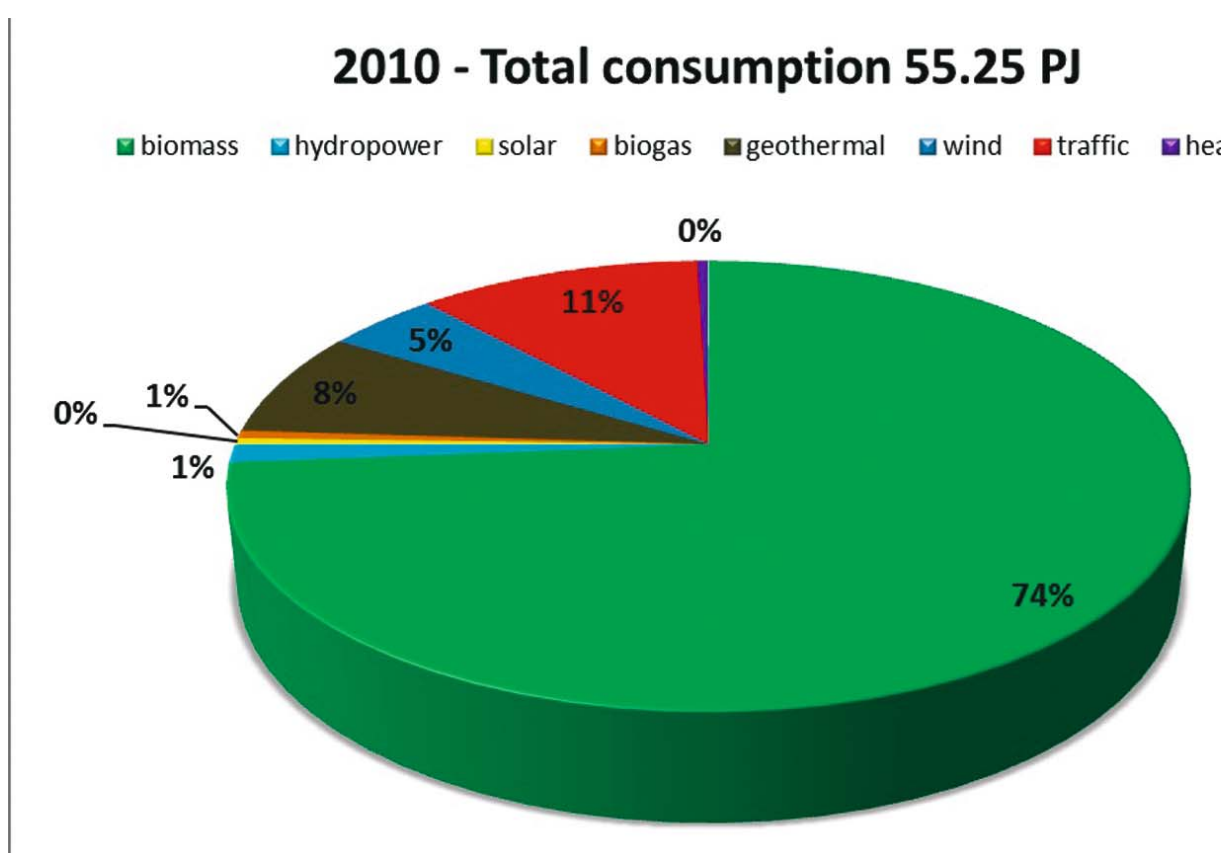




\section{0 - Planned total consumption 120.57 PJ}

$\square$ biomass $\square$ hydropower $\square$ solar $\square$ biogas घgeothermal $\square$ wind $\square$ traffic $\square$ heatpump

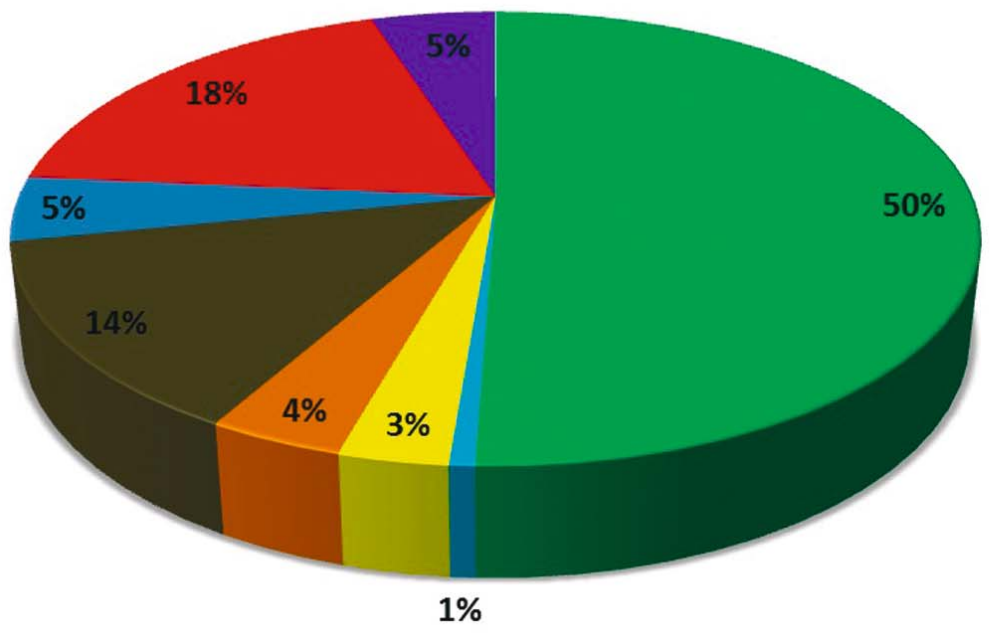

Figure 2: Renewable energy mix plans by the Hungarian national renewable action plan

The objectives of the REAP were defined by abilities and realistic accessible opportunities, aiming to economic development and creation of jobs.

Based on this, considerable step forward is expected in the whole renewable energy segment- compared to 2010 , the total gross use of renewable energy sources to be doubled until 2020. „Significant leap forward is estimated in every segment of the renewable energy sources. At the same time the development between 2010-2020 opens the door before further progress after 2020, creating the conditions for a long term low-carbon, green energy management. On the long term the renewable energy sources will be integral and essential elements of energetics. Taking account of the importance of national economy development of green energy management and its impact on employment, in the next ten years at least 150-200 thousand, within the renewable energy sector 70-80 thousand jobs are to be created as a realistic goal, which is based mainly rural employment extension." [9]

\section{SUGGESTIONS}

„The Renewable Energy Utilisation Action Plan” in several ways generated „lack” among the professionals. On the one hand it is understandable, since a strategy should be created globally considering the interaction of subsectors, political, social, cultural and other factors at once. However on the other hand the replacements of professional guidelines or solutions that often lack technical elaborateness are difficult to support. Application of the research results and inserting them into achievable programs are much more complex questions which should be in fact managed flexibly. The major criticism is not aimed to the above, but the professional, numerical part of the work. 
As an important cornerstone of the National Energy Strategy 2010-2030 the share of the renewable energy is to be considerably increased, which is a welcomed objective!

Motto: ,independence from the energy-dependence”.

The main instruments of the independence:

- $\quad$ increasing the energy saving and efficiency

- use of domestic national energy in the highest proportion

- safe nuclear energy and traffic electrification

- connecting to the European energy infrastructure

- donating renewable energy instead of taxing it,

- $\quad$ using the domestic carbon, lignite and hydrocarbon stocks environment friendly.

Our recommendations as well as our vision of renewable energy sources are analysed in the paper indicated in references.

Summarised, the major criticism of the Renewable Energy Action Plan is according to most experts that the use of hydropower (plants, reservoirs) is still a political issue rather than professional, as well as the use of biomass is alone not a solution to meet the criteria of 20/20/20. The third problem is that the strategy is not sufficiently bold, which a concern from the viewpoint of strategy is planning. What is the meaning of this?

Hungary is not in possession of significant mineral resources, our energy dependency is excessive, and the energy mix is not sufficiently diversified: the direction to move toward should be to aim for innovative technologies (in the perspective of 20-30 years); therefore as a knowledge-based society the country can compete with other nations.

The REAP is more of a vision, a concept or strategy rather than action plan: there are no clear concepts, business models, the cost of investments is not considered, or how the price of the energy production expected to change, what are the steps and the preferred conditions to achieve the values, what conditions must be met. With the absence of these answers, although contains valuable thoughts, the REAP not facilitates Hungary to reach the 20/20/20 goals.

HYPE suggest an honest and professional ground based reconciliation between professional organisations and the decision makers to get to common ground in the above mentioned questions and prepare a real action plan. In our report we have listed recommendations:

- Professional discussion on hydropower especially in case of large scale run-off-theriver and pumped-storage power plants

- Modification of regulation environment in a way that producers should be motivated to keep their balance that could lead to further tenders for instalment of wind power without increasing the balancing costs

- Favourizing small scale, local biomass utilization instead large scale firing in power plants

- Supporting RES based district heating to improve the competivity and to turn back the tendencies of customer number decrease

- Improving the regulatory environment of decentralized energy production making the licencing procedures easier,

- Supporting national research and development activities, small and mid size companies with local manufacturing. 


\section{ACKNOWLEDGMENTS}

The authors gratefully acknowledge the generous support of Hungarian Young Professionals in Energy, World Energy Council and the Hungarian Academy of Sciences Centre for Energy Research for helping this research getting realized.

\section{REFERENCES}

[1] Almási L., Bonda B., Gerse P., Hartmann B., Hegedús Z., Holló G., Talamon A., Vágó T., Vokony I.: HYPE report 2013 - Renewables/Energy/Planning/Policy HTTP://www.WEC.HU/WP-CONTENT/UPLOADS/2013/10/WEC_HYPE_REPORT_2013.PDF

[2] Memorandum European Commission Directorate-General Energy and Transport - Energy policy and the enlargement of the European Union HTTP://WWW.EUROPARL.EUROPA.EU/ENLARGEMENT/BRIEFINGS/43A1 EN.HTM

[3] Ministry of Rural Developmnet Hungary - Background Study Norvegian Foundation "green industrail innovation" program

[4] Ihász Ágnes (Budapest Business School - University of Applied Sciences) - The European Union's energy policy and the French way HTTP://ELIB.KKF.HU/EDIP/D 14283.PDF

[5] Jacek Saryusz-Wolski (Report - Committee on Foreign Affairs) - On towards a common European foreign policy on energy HTTP://WWW.EUROPARL.EUROPA.EU/SIDES/GETDOC.DO?PUBREF=-//EP//NONSGML+REPORT+A6-2007-0312+0+DOC $+\mathrm{PDF}+\mathrm{V} 0 / / \mathrm{EN}$

[6] A Legal Framework for International Energy Cooperation - The Energy Charter Treaty and Related Documents HTTP://WWW.ENCHARTER.ORG/FILEADMIN/USER_UPLOAD/DOCUMENT/EN.PDF

[7] Communication from the Comission to the European Council and the European Parliament (of 10 January 2007) - An Energy Policy for Europe HTTP://EUR-LEX.EUROPA.EU/LEGAL-CONTENT/EN/TXT/PDF/?URI=CELEX:52007DC0001\&FROM=EN

[8] Official Journal of the European Communities No L 61 - The Committee of 447/98 / EC Regulation

[9] Ministry of National Development - Hungary Renewable Energy Action Plan

[10] http://2010-2014.kormany.hu/download/6/b9/30000/RENEWABLE\%20ENERGY REPUBLIC\%20OF\%20HUNGAR Y\%20NATIONAL\%20RENEWABLE\%20ENERGY\%20ACTION\%20PLAN\%202010_2020.pdf

COMMISSION OF THE EUROPEAN COMMUNITIES - GREen PAPER: A EuRopeañ Strategy for Sustainable, Competitive and Secure Energy (Brussels, 8.3.2006.), HTTP://EUR-LEX.EUROPA.EU/LEGAL-CONTENT/EN/TXT/?QID=1433318086120\&URI=CELEX:52006DC0105

[11] The Florence School of Regulation Encyclopedia - EU Energy Legislation Packages, HTTP://FSR-ENCYCLOPEDIA.EUI.EU/EU-ENERGY-LEGISLATION-PACKAGES/

\section{APPENDIX}

\begin{tabular}{|c|c|c|c|c|c|c|c|c|c|c|c|c|c|c|c|c|c|c|c|c|c|c|c|}
\hline & & \multicolumn{2}{|c|}{2010} & \multicolumn{2}{|c|}{2011} & \multicolumn{2}{|c|}{2012} & \multicolumn{2}{|c|}{2013} & \multicolumn{2}{|c|}{2014} & \multicolumn{2}{|c|}{2015} & \multicolumn{2}{|c|}{2016} & \multicolumn{2}{|c|}{2017} & \multicolumn{2}{|c|}{2018} & \multicolumn{2}{|c|}{2019} & \multicolumn{2}{|c|}{2020} \\
\hline & & $\mathrm{MW}$ & GWhi & $\mathrm{MW}$ & GWhi & MW & GWhi & $\mathrm{MW}$ & GWhi & $\mathrm{MW}$ & GWhi & MW & GWhi & MW & GWhi & $\mathrm{MW}$ & GWhi & MW & GWhi & $\mathrm{MW}$ & GWhi & $\mathrm{MW}$ & GWh \\
\hline \multirow{5}{*}{ Hydropower } & Total & 51 & 194 & 51 & 194 & 51 & 194 & 51 & 194 & 51 & 194 & 52 & $196 !$ & 56 & 209 & 60 & 221 & 61 & 223 & 67 & 238 & 66 & 238 \\
\hline & $<1 \mathrm{MW}$ & 3 & 51 & 3. & 51 & 3 & 5 & i & 51 & 3 & 51 & 4 & 81 & 4 & 81 & 4 & 81 & 5 & 101 & 6 & 13 ! & 6 & 12 \\
\hline & $1 \mathrm{MW}-10 \mathrm{MW}$ & 9 & 301 & 9 & 301 & 9 & 30 & 9 & 301 & 9 & 30 & 9 & 301 & 13 & 43 & 18 & 551 & 18 & 55 & 22 & 671 & 22 & 67 \\
\hline & $>10 \mathrm{MW}$ & 39 & 158 & 39 & 158 & 39 & 158 & 39 & 158 & 39 & 158 & 39 & 158 & 39 & 158 & 39 & 158 & 39 & 158 & 39 & 158 & 39 & 158 \\
\hline & Pump & - & -1 & - & -1 & - & -1 & - & -1 & - & -1 & - & -1 & - & -1 & - & -1 & - & -1 & 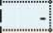 & -1 & 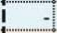 & \\
\hline \multicolumn{2}{|l|}{ Geothermal } & 0 & 01 & 0 & 01 & 0 & 0 & 4 & 29 & 4 & 29 & 4 & 29 & 8 & 57 & 8 & 571 & 57 & $410_{1}$ & 57 & 410 & 57 & 410 \\
\hline \multirow{3}{*}{ Solar } & Total & 0 & 21 & 2 & 5 & 6 & 9 & 9 & 14 & 14 & 20 & 19 & $26 !$ & 25 & 33 & 32 & 42 & 41 & 54 & 52 & 67 & 63 & 81 \\
\hline & PV & 0 & 21 & 2 & 51 & 6 & 91 & 9 & 141 & 14 & 201 & 19 & 261 & 25 & 331 & 32 & 42 & 41 & $54 !$ & 52 & 67 & 63. & 81 \\
\hline & Concentrated & 0 & 01 & 0 & 0 & 0 & 0 & 0 & 01 & 0 & 0 & 0 & 01 & 0 & 01 & 0 & 01 & 0 & 0 & 0 & 01 & 0 & 0 \\
\hline \multicolumn{2}{|c|}{ Tide and flow, wave } & - & 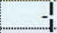 & - & i & - & -1 & - & -1 & $\therefore$ & 1 & - & I & - & -1 & - & -1 & - & 1 & - & 1 & - & \\
\hline \multirow{3}{*}{ Wind } & Total & 330 & 6921 & 393 & 692 & 445 & 9291 & 552 & 1150 & 568 & 13031 & 577 & 1377 & 588 & 1404 & 701 & 14501 & 719 & 14831 & 730 & 1504 & 750 & 1545 \\
\hline & On-shore & 330 & 692 & 393 & 692 & 445 & 929 & 552 & 1150 & 568 & 1303 & 577 & 1377 & 588 & 1404 & 701 & 1450 & 719 & 1483 & 730 & 1504 & 750 & 1545 \\
\hline & Off-shore & 7 & -1 & 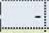 & -1 & 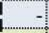 & -1 & 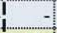 & -1 & 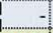 & -1 & 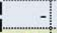 & -1 & 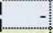 & -1 & is & -1 & 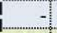 & -1 & 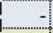 & -1 & - & \\
\hline \multirow{4}{*}{ Biomass } & Total & 374 & 1955 & 377 & 1971 & 381 & 1995 & 399 & 2097 & 471 & 2524 & 420 & 22501 & 329 & 17511 & 460 & 2492 & 535 & $2935 \mathrm{I}$ & 578 & 31911 & 600 & 3324 \\
\hline & Solid & 360 & 1870 & 360 & 1870 & 360 & 1870 & 373 & 1942 & 439 & 2328 & 377 & 1988 & 266 & 1362 & 387 & 2041 & 455 & 2434 & 484 & 2595 & 500 & 2688 \\
\hline & Biogas & 14 & $85 !$ & 17 & 101 & 21 & 125 & 26 & 155 & 32 & 196 & 43 & 262 & 63 & 389 & 73 & 451 & 80 & 501 & 94 & 596 & 100 & 636 \\
\hline & Liquid & 0 & oi & 0 & oi & 0 & oi & 0 & oi & 0 & 이 & 0 & oi & 0 & oi & 0 & oi & 0 & oi & 0 & & o & 0 \\
\hline \multicolumn{2}{|c|}{ Renewable electric } & 755 & 2843 & 823 & 2862 & 882 & 3127 & 1015 & 3484 & 1109 & 4069 & 1072 & 3878 & 1006 & 3453 & 1262 & 4262 & 1414 & 5105 & 1483 & 5410 & 1537 & 5597 \\
\hline \multicolumn{2}{|c|}{ Cogenerated heat- and electric p. } & 20 & 110 ] & 22 & 126 & 25 & 142 & 44 & 258 & 74 & 437 & 120 & 719! & 225 & 1307 & 332 & 1947! & 432 & 2611 & 427 & 2863 & 493 & 2990 \\
\hline
\end{tabular}

Table 1. The renewable energy mix detailed plans between 2010-2020 